\title{
Neonatal Profile and Outcome in Neonatal Intensive Care Unit Sanglah Hospital
}

\author{
Kirana Dyah Larasati Budhiarta, I Made Kardana \\ Department of Child Health, Sanglah Hospital, Faculty of Medicine, Udayana University, Denpasar, Indonesia \\ Email address: \\ kiranabudiharta@gmail.com (K. D. L. Budhiarta), made_kardana@yahoo.com (I M. Kardana)

\section{To cite this article:} \\ Kirana Dyah Larasati Budhiarta, I Made Kardana. Neonatal Profile and Outcome in Neonatal Intensive Care Unit Sanglah Hospital. \\ American Journal of Pediatrics. Vol. 6, No. 3, 2020, pp. 289-294. doi: 10.11648/j.ajp.20200603.29
}

Received: June 27, 2020; Accepted: July 9, 2020; Published: July 23, 2020

\begin{abstract}
Children face the highest risk of dying in their first month of life, at an average global rate of 2.5 million deaths in 2018. The highest neonatal mortality rate in 2018 occurred in Sub-Saharan Africa which reached 28 deaths per 1000 live births, followed by East Mediaterania with 25 deaths per 1000 live births. Meanwhile, based on Central Bureau of Statistics, the neonatal mortality rate in Indonesia were 15 deaths per 1000 live births in 2017 . More than $80 \%$ death in neonates caused by 3 preventable factors such as complication of prematurity, complication of birth like asphyxia and neonatal infection (such as sepsis and pneumonia). Furthermore intensive care unit play crucial role in critically ill neonate. In this study we aimed to determine profile and outcome of neonates treated in Neonatal Intensive Care Unit (NICU) of Sanglah Hospital. This was a descriptive cross sectional study and data was taken retrospectively from medical record of neonates treated in NICU during 2019. We got 393 neonates admitted in NICU, but forty patients were excluded due to readmission and insufficient data. Finally there were $208(62.1 \%)$ male neonates and 127 (37.9\%) female neonates, with 208 subjects were premature neonates ( $<37$ weeks). Their median length of stay was 7 days. Most cases were treated due to respiratory distress (84.1\%). In 2019, we found 111 neonates passed away with sepsis as the most common cause of neonatal death. Neonates treated in NICU were dominated by premature neonates, male and low birth weight ( $<2500$ gram). There was 28.2\% neonatal death in 2019.
\end{abstract}

Keywords: Profile, Outcome, Neonates, NICU

\section{Introduction}

Children face the highest risk of dying in their first month of life, at an average global rate of 2.5 million deaths in 2018. [1]. Data in 2018 showed that neonatal mortality accounts for almost 47 percent of all children death underfive years old [2]. This rate, compared to 1990, declined from 5 million deaths in 1990 to 2.5 million deaths in 2018. There were 7.000 neonatal deaths, whom one third died on the day of their birth and three quarters of them died in the first week of life [1].

The highest neonatal mortality rate in 2018 occurred in Sub-Saharan Africa which reached 28 deaths per 1000 live births. This was followed by East Mediaterania with 25 deaths per 1000 live births. Meanwhile, based on Central Bureau of Statistics, the neonatal mortality rate in Indonesia were 15 deaths per 1000 live births in 2017 [2]. United Nations (UN) launched a continuation of Millennium Development Goals (MDGs) program, the Sustainable
Development Goals (SDGs), in which Indonesia participated in agreement with 193 countries. In that agreement, one of the targets listed is to reduce neonatal mortality not more than 12 deaths per 1000 live births [3].

More than $80 \%$ of neonatal deaths were caused by 3 things that could be prevented, such as complication of prematurity, birth complications such as asphyxia and neonatal infections such as sepsis and pneumonia. Referring to this, UNICEF's strategy is to focus on quality postnatal care, corcerning special care for critically ill neonates in neonatal intensive care unit (NICU) [3]. The neonatal intensive care room has important role in the perinatal care of critically ill neonates [1].

Referring to this, baseline data such as characteristic and laboratory profile as well as outcome of critically ill neonates are needed to be studied in further research as reference to determine predictors. In this study we aimed to determine the profile and outcomes of neonates being treated in the intensive care room at Sanglah Hospital in 2019. 


\section{Method}

This was a descriptive cross-sectional study conducted in Neonatology Division of Sanglah Hospital with secondary data were neonates treated in neonatal intensive care room (NICU) from January to December 2019. Inclusion criteria were all critically ill neonates treated in NICU Sanglah Hospital. Exclusion criteria in this study were patients with incomplete medical record, patients who died before the infection markers were performed and re-admission.

Sampling was done by total purposive sampling technique. The sample size was calculated by using the proportion formula and the minimum required sample size was 100 neonates. This research has been approved by Research Ethics Commission of Medical Faculty Udayana University/ Sanglah Hospital Denpasar No. 1393/ UN14.2.2. VII. 14/ LP/ 2020. The operational definitions of the variables in this study were as follow:

1. Gestational age was calculated from the first day of mother's last menstruation until the baby was born or from the result of ultrasound examination. Gestational age was grouped into $<37$ weeks and $>37$ weeks (ordinal scale).

2. Birth weight was neonatal body weight at birth whom was weighed shortly after birth in grams. Birth weight was grouped into 4, namely: (ordinal scale).

i. Extremely low birth weight (ELBW) if $<1000$ grams.

ii. Very low birth weight (VLBW) if 1000-1499 grams.

iii. Low birth weight (LBW) if 1500-2499 grams.

iv. Normal birth weight if $>2500$ grams.

3. Leukocyte is the number of white blood cells obtained from the results of first complete blood count when the patient admitted to NICU, expressed in units of $10^{3} / \mu \mathrm{L}$ (numerical scale).

4. Mean platelet volume (MPV) is the average value of platelet, expressed in units of fL (numerical scale).

5. Platelet lymphocyte ratio (PLR) was the value obtained from dividing the number of platelets by lymphocytes (numerical scale).

6. Neutrophil lymphocyte ratio (NLR) was a value obtained from the division of the number of neutrophils with lymphocytes (numerical scale).

7. The number of platelets was the number of platelets, expressed in units of $10^{3} / \mathrm{uL}$ (numerical scale).

8. Lymphocyte count was the number of lymphocytes obtained from the results of first complete blood count at the time the patient was diagnosed as neonatal sepsis, expressed in units of $10^{3} / \mathrm{uL}$ (numerical scale).

9. Gender was the sex of the neonate based on phenotype, grouped into male and female (nominal scale).

10. Output was the patient's condition when discharged from NICU, grouped into survived and death (nominal scale).

11. IT Ratio was comparison between immature neutrophils to the total number of neutrophils in peripheral blood smear (numerical scale).

12. Procalcitonin was an early marker of bacterial sepsis and was a calcitonin-forming pro-hormone obtained from peripheral blood test, expressed in units of $\mathrm{ng} / \mathrm{mL}$ (numerical scale).

13. Blood sugar level was the concentration of glucose in blood obtained from the result of first blood examination when the patient admitted to NICU in $\mathrm{mg} / \mathrm{dL}$ units (numerical scale).

14. Vacuolization was the presence of vacuolization, which defined as an empty area in the cytoplasm that could be caused by severe infection, found in the peripheral blood smear (nominal scale).

15. Toxic granulation defined as neutrophil cytoplasmic abnormality in the form a large granulla (hypergranula), coarser than normal granule, darker in color (blue black or purple) that appeared on the peripheral blood smear (nominal scale).

16. Referral defined as case which was referred from other health workers / institutions (nominal scale).

17. Early-onset neonatal sepsis (EONS) defined as clinical syndrome in the form of at least 1 clinical symptom such as letargis, rapid breathing, temperature instability that arises due to systemic inflammatory response or minimum 2 indicators of infection markers that occurs due to infection, developed below 72 hours after birth (nominal scale).

18. Late-onset neonatal sepsis (LONS) defined as clinical syndrome in the form of at least 1 clinical symptom such as letargic, rapid breathing, temperature instability that arise due to systemic inflammatory response or minimum of 2 indicators of infection markers that occurs due to infection developed after 72 hours after birth (nominal scale).

19. Respiratory distress defined as symptoms of respiratory disorder supported by Down Score (nominal scale).

20. Surgical cases defined as cases involving pediatric surgeon management (nominal scale).

21. Congenital abnormalities defined as structural abnormalities acquired from birth (nominal scale).

22. Blood culture was the result of blood culture obtained while admitted in NICU (nominal scale).

23. Duration of stay was the duration of patient treated until death or recover (numerical scale).

24. Re-admission defined as patient whom had been treated in NICU before then was re-treated again during the study period.

All data was analyzed by SPSS program then presented in narrative and table form. Categorical data was presented as percentages while numerical data was presented as median and interquartile.

\section{Result}

We found 393 neonates treated in NICU Sanglah Hospital during the study period (January to December 2019). Forty 
neonates were excluded from this study because 14 of them did not have complete data and 26 others were re-admission patients. Thus total number of our samples were 353 neonates.

We got 208 (62.1\%) male and 127 (37.9\%) female neonates. Total 208 subjects were premature neonates $(<37$ weeks) and 127 subjects were mature neonates. The median length of stay was for 7 days. Clinical characteristics of the study data are shown in table 1.

Table 1. Clinical characteristic of samples.

\begin{tabular}{ll}
\hline Variables & $\mathbf{N}=\mathbf{3 5 3}$ \\
\hline Gestational age $^{\mathrm{a}}$ (weeks) & $34(24-43)$ \\
$<37$ weeks $^{\mathrm{b}}$ & $218(61.8)$ \\
$>37$ weeks $^{\mathrm{b}}$ & $135(38.2)$ \\
Gender $^{\mathrm{b}}$ & \\
Male & $218(61.8)$ \\
Female & $135(38.2)$ \\
Birth weight & \\
$<1000$ & \\
$1000-1499$ & $29(8.2)$ \\
$1500-2499$ & $85(24.1)$ \\
$>2500$ & $112(31.7)$ \\
Reason of admission in NICU & $127(36)$ \\
Respiratory distres & \\
EONS & $297(84.1)$ \\
LONS $_{\text {Surgical case }}^{\mathrm{b}}$ & $291(82.4)$ \\
Congenital malformation & $33(9.3)$ \\
Referal case & \\
Etiology of mortality & \\
Sepsis & $83(17.8)$ \\
Prematurity & $87(24.6)$ \\
Severe Asphyxia & $166(47)$ \\
Congenital malformation & \\
Others & $75(67.57)$ \\
Length of stay $^{\mathrm{b}}$ & $11(9.9)$ \\
\hline
\end{tabular}

${ }^{\mathrm{a}}$ median (minimum-maksimum), ${ }^{\mathrm{b}} \mathrm{n}(\%)$.

The first peripheral blood laboratory panel taken from neonates treated in NICU showed median of leukocytes $13.75 \times 10^{3} / \mu \mathrm{L}$, median of IT ratio 0.13 , median of procalcitonin 0.88 . Neonates with positive vacuolation in peripheral blood smear were found in $13.9 \%$ neonates meanwhile positive toxic granulation was found in $7.1 \%$ of cases. Most of the blood culture results were sterile (no growth of microorganism). Laboratory profile can be seen in table 2 .

Table 2. Laboratory profile.

\begin{tabular}{ll}
\hline Variables & $\mathbf{N}=\mathbf{3 5 3}$ \\
\hline Blood Panel $^{\mathrm{a}}$ & \\
Leukocyte $\left(10^{3} / \mu \mathrm{L}\right)$ & $13.75(1.28-100.20)$ \\
Neutrophil $\left(10^{3} / \mu \mathrm{L}\right)$ & $6.36(0.08-55.24)$ \\
Limphocyte $\left(10^{3} / \mu \mathrm{L}\right)$ & $3.69(0.23-68.3)$ \\
IT Ratio & $0.13(0.01-2.96)$ \\
MPV $(\mathrm{fL})$ & $6.63(4.45-16.95)$ \\
Hemoglobin $(\mathrm{g} / \mathrm{dL})$ & $15.69(2.8-23.89)$ \\
Platelet $\left(10^{3} / \mu \mathrm{L}\right)$ & $199.5(3.92-647.20)$ \\
PLR & $49.22(0.42-505.53)$ \\
NLR & $1.62(0.01-37.39)$ \\
Procalcitonin $(\mathrm{ng} / \mathrm{mL})$ & $0.88(0.04-531)$ \\
Blood sugar $(\mathrm{mg} / \mathrm{dL})$ & $90(7-687)$ \\
\hline
\end{tabular}

\begin{tabular}{ll}
\hline Variables & $\mathbf{N}=\mathbf{3 5 3}$ \\
\hline Vacuolization $^{\mathrm{b}}$ & \\
Positive & $49(13.9)$ \\
Negative $^{\text {Toxic granule }}{ }^{\mathrm{b}}$ & $304(86.1)$ \\
Positive & \\
Negative & $25(7.1)$ \\
Blood culture & \\
No Growth & $328(92.9)$ \\
Staphylococcus spp & \\
Klebsiella Pneumoniae $_{\text {Acinobacter Baumanii }}$ & $320(90.7)$ \\
Other & $11(3.1)$ \\
Pseudomonas Aeruginosa & $6(1.7)$ \\
\hline
\end{tabular}

Respiratory distress $(84.1 \%)$ dominated most cases in NICU, followed by EONS (82.4\%). In 2019, there were 111 $(28.2 \%)$ neonates died with sepsis $(67.57 \%)$. We found the median age of deceased neonates was younger than the survive neonate ie. 32 weeks and 35 weeks respectively and dominated by male $(68.5 \%)$. The median birth weight was also lighter in the deceased ie. 1700 gram while for those who were survived the median birth weight was found to be 2200 gram.

As many as $58.6 \%$ neonates with respiratory distress were able to survive. Likewise in EONS cases, $56.7 \%$ of neonates with diagnosis of EONS were able to survive. Meanwhile 18 neonates with LONS died. Sixty-three of the deceased neonates were referral cases. Comparison of patient profiles and outcomes can be seen in table 3 .

Table 3. Comparison of clinical profile and outcome.

\begin{tabular}{|c|c|c|}
\hline Variables & Survive $(\mathrm{N}=\mathbf{2 4 2})$ & $\operatorname{Died}(N=111)$ \\
\hline Gestational age $^{\mathrm{a}}$ (weeks) & $35(25-42)$ & $34(24-43)$ \\
\hline$<37$ weeks $^{\mathrm{b}}$ & $144(40.8)$ & $74(21)$ \\
\hline$>37$ weeks $^{\text {b }}$ & $98(27.8)$ & $37(10.5)$ \\
\hline \multicolumn{3}{|l|}{ Gender $^{\mathrm{b}}$} \\
\hline Male & $153(70.1)$ & 65 (29.9) \\
\hline Female & $89(65.9)$ & $46(32.1)$ \\
\hline Birth weight ${ }^{\text {b }}$ (gram) & $2200(650-4250)$ & $1700(450-4350)$ \\
\hline$<1000^{\mathrm{b}}$ & $12(3.4)$ & $17(4.8)$ \\
\hline $1000-1499^{b}$ & $53(15)$ & $32(9.1)$ \\
\hline $1500-2499^{b}$ & $80(22.7)$ & $32(9.1)$ \\
\hline$>2500^{\mathrm{b}}$ & $97(27.5)$ & $30(8.5)$ \\
\hline \multicolumn{3}{|l|}{ Respiratory distress $^{a}$} \\
\hline Yes & $207(58.6)$ & $90(25.5)$ \\
\hline No & $35(9.9)$ & $21(5.9)$ \\
\hline \multicolumn{3}{|l|}{ EONS $^{\mathrm{a}}$} \\
\hline Yes & $200(56.7)$ & $91(25.8)$ \\
\hline No & $42(11.9)$ & $2(5.7)$ \\
\hline \multicolumn{3}{|l|}{ LONS $^{\mathrm{a}}$} \\
\hline Yes & $15(4.2)$ & $18(5.1)$ \\
\hline No & $227(64.3)$ & $93(26.3)$ \\
\hline \multicolumn{3}{|l|}{ Surgical case ${ }^{a}$} \\
\hline Yes & $41(11.6)$ & $22(6.2)$ \\
\hline No & $201(56.9)$ & $89(25.2)$ \\
\hline \multicolumn{3}{|l|}{ Congenital malformation $^{\mathrm{a}}$} \\
\hline Yes & $58(16.4)$ & $29(8.2)$ \\
\hline No & $184(52.1)$ & $82(23.2)$ \\
\hline \multicolumn{3}{|l|}{ Referal case $^{\mathrm{a}}$} \\
\hline Yes & $103(29.2)$ & $63(17.8)$ \\
\hline No & 139 (39.4) & $48(13.6)$ \\
\hline
\end{tabular}

${ }^{\mathrm{a}}$ median (minimum-maximum), ${ }^{\mathrm{b}} \mathrm{n}(\%)$. 
Table 4. Comparison of laboratory profile and outcome.

\begin{tabular}{|c|c|c|}
\hline Variables & Survive $(\mathrm{N}=242)$ & Died $(N=111)$ \\
\hline Leukocytes $^{\mathrm{a}}\left(10^{3} / \mu \mathrm{L}\right)$ & $13.49(1.28-100.20)$ & $13.77(1.74-72.22)$ \\
\hline $\operatorname{Neutrophil}^{\mathrm{a}}\left(10^{3} / \mu \mathrm{L}\right)$ & $6.61(0.08-40.93)$ & $5.56(0.08-55.24)$ \\
\hline Limphocytes $^{\mathrm{a}}\left(10^{3} / \mu \mathrm{L}\right)$ & $3.63(0.52-68.3)$ & $3.95(0.23-61.71)$ \\
\hline $\mathrm{MPV}^{\mathrm{a}}(\mathrm{fL})$ & $6.45(4.45-16.51)$ & $7(5.45-16.95)$ \\
\hline Hemoglobin (g/dL) & $15.70(2.8-23.89)$ & $15.67(4.12-21.94)$ \\
\hline Platelet $\left(10^{3} / \mu \mathrm{L}\right)$ & $219.70(3.92-647.2)$ & $168.8(5.37-537.3)$ \\
\hline $\mathrm{NLR}^{\mathrm{a}}$ & $1.74(0.03-21.89)$ & $1.49(0.01-37.39)$ \\
\hline PLR $^{\mathrm{a}}$ & $61.09(1.71-411.27)$ & $33.34(0.42-505.53)$ \\
\hline IT Ratio $^{a}$ & $0.12(0.01-2.06)$ & $0.14(0.01-2.96)$ \\
\hline \multicolumn{3}{|l|}{ Vacolization $^{\mathrm{a}}$} \\
\hline Positive & $34(9.6)$ & $15(4.2)$ \\
\hline Negative & $208(58.9)$ & $96(27.2)$ \\
\hline \multicolumn{3}{|l|}{ Toxic granule $^{\mathrm{a}}$} \\
\hline Positive & $18(5.1)$ & $7(2)$ \\
\hline Negative & $224(63.5)$ & $104(29.5)$ \\
\hline Procalcitonin $^{\mathrm{a}}(\mathrm{ng} / \mathrm{mL})$ & $0.88(0.07-531)$ & $1.36(0.04-141.80)$ \\
\hline Blood sugar $^{\mathrm{a}}(\mathrm{mg} / \mathrm{dL})$ & $88.5(10-687)$ & $100.02(7-483)$ \\
\hline
\end{tabular}

${ }^{a}$ median (minimum-maximum), ${ }^{b} \mathrm{n}(\%)$.

In this study, laboratory profile was not much different between survived and dead neonates. In survived neonates, the median leukocyte was $13.49 \times 10^{3} / \mu \mathrm{L}$, the median IT ratio was 0.12 , the median procalcitonin was $0.88 \mathrm{ng} / \mathrm{mL}$. Whereas in deceased neonates, the median leukocyte was $13.77 \times 10^{3} / \mu \mathrm{L}$, the median IT ratio was 0.14 and the median procalcitonin was $1.36 \mathrm{ng} / \mathrm{mL}$. Comparison of laboratory profile and patient outcomes can be seen in table 4 .

\section{Discussion}

In this study, the median age of deceased neonates was younger than that of the survived neonates ie 32 weeks and 35 weeks respectively. Most of the neonates who died were male $(68.5 \%)$. The median birth weight was also found to be smaller in the deceased group ie 1700-gram while for those survived the median birth weight was found to be 2200 gram. Laboratory panels between survived and deceased neonates are not very different. As many as $58.6 \%$ of neonates with respiratory distress survived. Likewise in EONS cases, $56.7 \%$ of neonates with diagnosis of EONS survived. There were 18 neonates with LONS who died. Sixty-three of deaceased neonates were referral cases. The comparison of patient profiles and outcomes can be seen in Table 3.

In this study, laboratory profile was not much different between survived and dead neonates. In survived neonates, the median leukocytes was $13.49 \times 10^{3} / \mu \mathrm{L}$, the median IT ratio was 0.12 , the median procalcitonin was $0.88 \mathrm{ng} / \mathrm{mL}$. Whereas in neonates who died, the median leukocyte was $13.77 \times 10^{3} / \mu \mathrm{L}$, the median IT ratio was 0.14 and the median procalcitonin was $1.36 \mathrm{ng} / \mathrm{mL}$. Comparison of laboratory profile and patient outcomes can be seen in Table 4 .

Respiratory distress $(84.1 \%)$ was the most dominated cases followed by an EONS $82.4 \%$, congenital abnormalities $24.6 \%$, and surgical cases $17.8 \%$. Meanwhile study in Nepal, India obtained sepsis as the main reason for NICU treatment $(32.6 \%)$ followed by prematurity $(23.8 \%)$ and asphyxia
$(20.2 \%)[4]$.

Other studies showed that NICU cases was dominated by prematurity with complications $(23 \%)$, asphyxia (19\%) and hyperbilirubinemia (18\%) [5]. Respiratory distress was the main indication of NICU treatment in Sanglah General Hospital probably due to the need of respiratory support machine which only available in NICU while the condition of prematurity can be treated in level II treatment room which also available in this hospital.

Total 111 neonates died during 2019 so that the mortality rate was $28.2 \%$ in NICU. We also found that 393 patients died with sepsis $(67.57 \%)$. This figure showed high mortality rate in neonates. Similar result was found in Ethiopia, which neonatal deaths was found $13.3 \%$ and low birth weight, neonatal sepsis and hypothermia were the three main causes of death [9].

A study examining neonatal deaths in developing countries stated that government support is needed to improve the quality of child care at birth and post-birth by supporting the availability of health facilities, especially in the care of newborns [10]. A systematic study stated that infection in neonates still a global problem, especially in low income countries [11]. A study found that the predictors of neonatal sepsis could be grouped into 2 factors, namely maternal factors, such as parity $(\mathrm{p}<0.027)$; mode of delivery $(\mathrm{p}<0.001)$; bleeding $(\mathrm{p}<0.001)$; premature rupture of membranes $(\mathrm{p}<0.001)$ and neonates factors, such as APGAR score at the first and fifth minutes $(\mathrm{p}<0.001)$; neonatal resuscitation $(p<0.004)$; duration of treatment in health facility $(p<0.001)$; age while admitted $(p<0.001)$ [12]. Effort can be made to encourage the optimization of maternal antenatal care which help to identify risk factors during prenatal and postnatal care, so appropriate interventions can be given immediately to needed neonates.

The median profile of laboratory profile when the neonate admitted in NICU were hemoglobin $15.69 \mathrm{mg} / \mathrm{dL}$, platelet $199.5 \times 10^{3} / \mu \mathrm{L}$ and blood sugar $90 \mathrm{mg} / \mathrm{dL}$. As for the markers of infection used in neonates were leukocytes, IT ratio, blood smears and procalcitonin. The median leukocyte level in this study was $13.75 \times 10^{3} / \mu \mathrm{L}$, the median of IT ratio was 0.13 , neonate with positive vacuolation in peripheral blood smear were $49(13.9 \%)$ subjects and $25(7.1 \%)$ with positive granule toxic. While the median levels of procalcitonin was $0.88 \mathrm{ng} / \mathrm{dL}$ with minimum value of $0.04 \mathrm{ng} / \mathrm{mL}$ and maximum $531 \mathrm{ng} / \mathrm{mL}$. The profile of infection markers in neonates is crucial because sepsis is one of the most common etiology of neonatal mortality as shown in previous studies [13].

In recent studies, many have reported simple and inexpensive markers of infection that are, namely PLR, NLR and MPV [13]. In this study, the median MPV level was 6.63 $\mathrm{fL}$, the median PLR was 49.22 and the median NLR was 1.62 . The median value of infection markers in all our neonates didn't show infection. While the clinical diagnosis of EONS was quite high in this study. This could be explained that the diagnosis of EONS in our study was based on clinical symptoms. In addition, blood culture as the gold standard for 
diagnosis of sepsis required long processing time. Thus there is often overdiagnosis of sepsis considering neonatal sepsis has high risk of mortality. Another thing that might happen is the possibility of nosocomial infection, an infection obtained in hospital. A study showed that nosocomial infections occured 100 times more than infections obtained intra-uterine or during the birth process [14].

This study also examined the outcomes of neonates admitted in NICU, 74 (21\%) pre-term neonates and 37 $(10.5 \%)$ full-term neonates died. In accordance with previous studies which prematurity was one of the most common causes of death in neonates [13]. The median birth weight of survived neonate was 2200 grams while the deceased neonate was 1700 grams. Babies with lower birth weight tend to have higher mortality risk. Low birth weight was the biggest cause (70\%) of neonatal death especially in developing countries [15]. In low birth weight and premature neonate, the risk of hypothermia increases. Heat loss in low birth weight infant was caused by multi factorial, including the ratio of body mass and surface, inadequate storage of subcutaneous fat, reduced storage of brown adipose tissue (BAT), underdeveloped skin (premature skin), increased skin permeability, increased trans-epidermal water loss, poor vasomotor control and extension baby posture $[15,16]$.

Total 63 cases $(17.8 \%)$ of deceased neonates were referral cases, while 48 cases $(13.6 \%)$ were not referral cases. The higher mortality rate in referral neonates was likely due to the severity of clinical conditions in neonates thus required treatment in referral center such as Sanglah Hospital. Another possibility was related to the eligibility of neonates during transport. Six important evaluations should be carried out before transportation namely STABLE (Sugar and safe care, temperature, airway, blood pressure, lab work, emotional support) [17].

Limitation of our study, we did not analyze the relationship between profiles and outcomes so it couldn't describe the predictor factors.

\section{Conclusion}

This study concluded that neonates treated in NICU were dominated by premature neonates, especially male neonates and neonates with birth weight $<2500$ grams. Death occur more frequently in neonates $<37$ weeks, in male neonates and in referral cases. There was not much different in the markers of infection from laboratory panel. Total 111 neonates died thus the mortality rate during 2019 was $28.2 \%$ in NICU during this period. Improving the quality of facilities and human resources in NICU should be carried out on an ongoing basis, especially in effort to reduce the incidence of infections in neonates. Further research should be carried out to find the predictors of critically ill neonatal outcomes.

\section{Funding}

Nil.

\section{References}

[1] Neonatal mortality [Internet]. UNICEF DATA. [cited 2020 May 8]. Available from: https://data.unicef.org/topic/childsurvival/neonatal-mortality/.

[2] Yembise Y. S, Suhariyanto, Yuwono M., Lumaksono A. 2018 Profil Anak Indonesia 2018. Jakarta: Kementerian Pemberdayaan Perempuan dan Perlindungan Anak (KPPPA).

[3] WHO | Under-five mortality [Internet]. WHO. World Health Organization; [cited 2020 May 8]. Available from: http://www.who.int/gho/child_health/mortality/mortality_und er_five_text/en/.

[4] Shah G. S., Shah L. R., Thapa A. Clinical profile and outcome of neonates admitted to the Neonatal Intensive Care Unit (NICU) at BPKIHS: A need for advanced neonatal care. Qatar Med J [Internet]. 2017 Feb 14 [cited 2020 May 8]; 2017 (1). Available https://www.ncbi.nlm.nih.gov/pmc/articles/PMC5474642/.

[5] Panda P. K. Clinical profile and outcome of newborns admitted to a secondary-level neonatal intensive care unit in tribal region of Odisha. J Clin Neonatol. 2019; 18 (3): 155-8.

[6] Unger A., Jagsch R., Baewert A., Winklbaur B., Rohrmeister K., Martin P. R., et al. Are male neonates more vulnerable to neonatal abstinence syndrome than female neonates? Gend Med. 2011; 8 (6): 355-64.

[7] Singh Kotwal Y. Neonatal morbidity and mortality in a neonatal intensive care unit: a hospital based prospective study. 2018; 2: 232-6.

[8] Kambarami R., Chidede O., Chirisa M. Neonatal intensive care in a developing country: outcome and factors associated with mortality. Cent Afr J Med. 2000; 46 (8): 205-7.

[9] Seid S. S., Ibro S. A., Ahmed A. A., Olani Akuma A., Reta E. Y., Haso T. K., et al. Causes and factors associated with neonatal mortality in Neonatal Intensive Care Unit (NICU) of Jimma University Medical Center, Jimma, South West Ethiopia. Pediatr Health Med Ther. 2019. 3; 10: 39-48.

[10] Sankar M. J., Natarajan C. K., Das R. R., Agarwal R., Chandrasekaran A., Paul V. K. When do newborns die? A systematic review of timing of overall and cause-specific neonatal deaths in developing countries. J Perinatol. 2016; 36 (Suppl 1): S1-11.

[11] Fleischmann-Struzek C., Goldfarb D. M., Schlattmann P., Schlapbach L. J., Reinhart K., Kissoon N. The global burden of paediatric and neonatal sepsis: a systematic review. Lancet Respir Med. 2018; 6 (3): 223-30.

[12] Adatara P., Afaya A., Salia S. M., Afaya R. A., Konlan K. D., Agyabeng-Fandoh E., et al. Risk Factors Associated with Neonatal Sepsis: A Case Study at a Specialist Hospital in Ghana [Internet]. Vol. 2019, The Scientific World Journal. Hindawi; 2019 [cited 2020 Jun 15]. p. e9369051. Available from: https://www.hindawi.com/journals/tswj/2019/9369051/.

[13] Sudhakar, Vijayalaxmi, Akhila. A Study of Laboratory Profile of Neonatal Sepsis at NICU (SNCU), Warangal. J Evid Based Med Healthc. 2016; 1: 1-3.

[14] Polin R. A., Saiman L. Nosocomial Infections in the Neonatal Intensive Care Unit. NeoReviews. 2003; 14 (3): e81-9. 
[15] Baghianimoghadam M. H., Baghianimoghadam B., Ardian N., Alizadeh E. Risk factors of low birth weight and effect of them on growth pattern of children up to sixth months of life: A cross-sectional study. J Educ Health Promot [Internet]. 2015 [cited 2020 May 29]; 4. Available from: https://www.ncbi.nlm.nih.gov/pmc/articles/PMC4456878/.
[16] Hypothermia in the Low Birth Weight Premature Infant [Internet]. Medscape. [cited 2020 Jun 15]. Available from: http://www.medscape.com/viewarticle/765543.

[17] The S. T. A. B. L. E. Program [Internet]. [cited 2020 Jun 16]. Available from: https://stableprogram.org/. 